\title{
Peningkatan karakter demokratis melalui Traditional Enggo Group Play Therapy pada anak usia TK
}

\author{
Andrianus Krobo ${ }^{* *}$ \\ Universitas Cendrawasih ${ }^{1}$ \\ *) Alamat korespondensi: Jl. Kamp Wolker, Jayapura, 99224, Indonesia; E-mail: krobozon@gmail.com
}

\begin{abstract}
Article History:
Received: 02/02/2021;

Revised: 24/02/2021;

Accepted: $24 / 02 / 2021$;

Published: 28/02/2021.
\end{abstract}

How to cite:

Krobo, A. (2021). Peningkatan

karakter demokratis melalui

Traditional Enggo Group Play

Therapy. Teraputik: Jurnal

Bimbingan dan Konseling, 4(3), pp. 400-414. DOI:

$10.26539 /$ teraputik-43558

This is an open
access article
distributed under the Creative
Commons 4.0 Attribution
License, which permits
unrestricted use, distribution,
and reproduction in any medium,
provided the original work is
properly cited. @ 2021 ,
Andrianus Krobo(s).

\begin{abstract}
Karakter demokratis perlu ditumbuhkan sejak usia dini karena merupakan pondasi awal terhadap kepribadiannya di masa yang akan datang. Tujuan dari penelitian ini, yaitu menjelaskan langkah-langkah Traditional Enggo Group Play Therapy dan untuk menjabarkan hasil peningkatan karakter demokratis anak usia Taman Kanak-kanak melalui Traditional Enggo Group Play Therapy. Metode penelitian menggunakan participatory action research. Hasil penelitian menunjukan terdapat peningkatan karakter demokratis anak, baik dari skor observasi dan angket, maupun analisis dokumentasi, catatan lapangan, dan wawancara. Dari data observasi, skor pra tindakan dua, sedangkan skor pada pertemuan keenam di siklus II adalah tujuh. Dari data angket, terdapat peningkatan jumlah anak yang memilki karakter demokratis, mulai dari 33\% dari lima belas anak pada pra tindakan, hingga 93\% pada siklus II. Hal ini berarti, Traditional Enggo Group Play Therapy dapat meningkatkan karakter demokratis anak usia Taman Kanak-Kanak.
\end{abstract}

\section{Keywords: Karakter Demokrasi, Play Therapy, Enggo}

\begin{abstract}
Abstrak: Democratic character needs to be cultivated from an early age because it is the initial foundation for his personality in the future. The purpose of this research is to explain the steps of Traditional Enggo Group Play Therapy and to describe the results of improving the democratic character of kindergarten age children through Traditional Enggo Group Play Therapy. The research method uses participatory action research. The results showed that there was an increase in the democratic character of children, both from the scores of observations and questionnaires, as well as documentation analysis, field notes, and interviews. From the observation data, the pre-action score was two, while the score at the sixth meeting in the second cycle was seven. From the questionnaire data, there was an increase in the number of children who had a democratic character, starting from $33 \%$ of the fifteen children in pre-action, to $93 \%$ in cycle II. This means that Traditional Enggo Group Play Therapy can improve the democratic character of Kindergarten age children.
\end{abstract}

Kata Kunci: Democratic Characters; Play Therapy, Enggo

\section{Pendahuluan}

Demokrasi penting bagi negara Indonesia yang memiliki nilai kemajemukan Suku, Agama, Ras, dan Antargolongan (SARA). Demokrasi berarti pemerintahan yang bersumber dari rakyat (Humaira, 2021), dengan menggunakan praktik intelegensi, atau usaha mencari nilai-nilai kebenaran (Idris, 2014). Demokrasi memunculkan penghormatan terhadap berbagai perbedaan (Harefa \& Fatolosa Hulu, 2020). Demokrasi memunculkan toleransi dan kedamaian (Sa'idi, 2017). Demokrasi sudah menjadi kebutuhan yang harus diimplementasikan dalam kehidupan bermasyarakat (Rosyad \& Maarif, 2020). Karena itu, masyarakat Indonesia diharapkan memiliki karakter demokratis, sesuai dengan sila keempat Pancasila yang bijaksana dalam kemusyawaratan. Herry B. Mayo, dalam (Ramadhan, 2021) mencatat indikator masyarakat demokratis di antaranya: (1) penyelesaian perselisihan dengan damai; (2) pergantian penguasa secara teratur; (3) pembatasan paksaan secara minimum; (4) pengakuan atas keanekaragaman; (5) jaminan penegakan keadilan; dan (6) upaya memajukan pengetahuan.

Faktanya, karakter demokratis tidak selalu terwujud dalam implementasi hubungan kemasyarakatan. Fenomena otoriter dan konflik tak jarang ditemui di masyarakat. Sebagai contoh, kasus pelanggaran HAM, operasi militer di Aceh, Timor Timur, Papua, dan masih banyak 
lagi, diikuti dengan kasus penghilangan aktivis sepanjang tahun 1997-1998 menunjukkan bentuk otoriter penguasa (Noor, 2017). Dampaknya, cukup sulit menyatukan Indonesia untuk bergerak sama-sama maju. Hal ini merupakan implikasi dari penyebab demokrasi yang belum berjalan semestinya sesuai dengan Pancasila. Demokrasi belum berjalan sepenuhnya ini disebabkan karena karakter demokrasi belum mendarah daging dan menjadi kepribadian bagi seluruh warga Indonesia. Sementara itu, guru BK memiliki peran untuk mewujudkan sekolah yang aman dan damai (Bilqis et al., 2019). Guru BK juga berperan dalam memberikan pendidikan karakter pada peserta didik.

Dalam bahasa Yunani, karakter artinya menandai nilai kebaikan dalam tingkah laku (Hendayani, 2019). Dalam Kamus Bahasa Indonesia, kata "karakter" diartikan tabiat, sifat-sifat kejiwaan, akhlak yang membedakan dengan orang lain (Sajadi, 2019). Karakter merupakan penilaian subjektif terhadap atribut kepribadian seseorang dari penerimaan masyarakat (Coon, dalam Kurnia, 2019). Karakter mengandung serangkaian attitudes, behaviors, motivation, dan skills (Zainal dan Sujak, dalam Piscarika et al., 2020). Dengan demikian, karakter dapat disimpulkan sebagai atribut kepribadian yang diberikan orang lain pada seseorang didasarkan pada perilaku yang dimunculkan secara berpola. Jika orang tersebut suka mendengarkan dan mendiskusikan bersama suatu masalah, maka orang tersebut dapat dikatakan memiliki karakter demokratis yang baik. Jika orang tersebut tidak mendengarkan orang lain dan memaksakan kehendaknya sendiri, maka orang tersebut memiliki karakter diktatorial atau sewenang-wenang.

Karakter demokrasi memiliki ciri-ciri (Nasution, 2018; Muslih \& Ulfah, 2020), antara lain: cerdas, beriman, mencintai bangsanya, tenggang rasa, berbudi pekerti, tanggung jawab, dan berorientasi ke masa depan. Sejalan dengan hal tersebut Mulyono (2017) menyebutkan karakteristik warga negara ideal, antara lain: 1) mampu mengenali masalah; 2) mampu bekerjasama dan bertanggung jawab; 3) mampu menghormati perbedaan budaya; 4) mampu berpikir kritis \& sistematis; 5) mau menyelesaikan konflik secara damai, tanpa kekerasan; 6) peka dan mempertahankan hak asasi manusia. Sikap demokratis mencakup empat indikator, yaitu toleransi, musyawarah, lapang dada, dan tanggung jawab (Hudayah \& Harmanto, 2021).

Salah satu cara agar masyarakat memiliki karakter demokratis adalah mengembangkan pendidikan karakter, khususnya karakter demokratis. Pendidikan karakter adalah penanaman nilai-nilai, mulai dari ilmu, kemauan, hingga tindakan untuk dapat melaksanakan nilai-nilai tersebut (Suwito, 2012). Perlunya pendidikan karakter demokratis juga tertuang dalam UU 20/2003 (Setiawati et al., 2020) tentang tujuan pendidikan dalam Sistem Pendidikan Nasional. Berdasarkan UU tersebut, tujuan pendidikan nasional adalah pengembangan karakter siswa.

Pendidikan karakter demokrasi ini sebaiknya diberikan kepada anak di jenjang Taman Kanak-kanak. Anak di usia jenjang Taman Kanak-kanak, sudah mulai melakukan kegiatan secara berkelompok melalui permainan (Nurmalitasari, 2015). Anak mulai belajar memahami \& tunduk dalam peraturan permainan secara disiplin (Sulaiman et al., 2019). Ketika anak melakukan inisiatif dalam permainan, anak belajar apakah kepentingannya diterima atau ditolak (initiative vs guilt) (Khoiruddin, 2018). Konflik membantu anak memahami bahwa temannya memiliki cara pandang dan kepentingan yang berbeda dengannya (Bilqis, 2017). Anak belajar empati dan toleran, menghargai hak orang lain, kooperatif, dan resiliensi menggunakan cara yang diterima secara sosial dalam menyelesaikan masalah (Maria \& Amalia, 2018). Karakter demokratis adalah turunan dari bidang sosial dalam Bimbingan dan Konseling. Anak yang sukses dalam pergaulan sosial yang baik akan memiliki akademik yang baik, moralitas yang baik, dan emosi yang baik (Saripah \& Bilqis, 2019).

Pendidikan dasar sebagai peletakan landasan perkembangan kepribadian anak, diharapkan mampu merujudkan generasi emas yang unggul dan berkarater Pancasila. Persiapan penataan Sumber Daya Manusia sejak usia dini merupakan hal yang mutlak perlu dilakukan demi mewujudkan cita-cita bangsa Indonesia di masa depan. Karakter yang perlu dikembangkan salah satunya adalah karakter demokratis (Fadlillah, 2016). Ketika anak besar, nilai moral akan menjadi superego (Hakim, 2020) yang mendarah daging untuk diterapkan secara otomatis hingga dewasa.

Lembaga penyelengara pendidikan dasar/ anak usia dini perjenjang usia yaitu (KB) kelompok bermain, (TK) taman kanak-kanak kesemuanya adalah lembaga PAUD yang berbasis pada kebutuhan anak (Hasanah, 2019). Pendidikan merangsang aspek perkembangan anak, 
baik aspek sosial emosional, seni, bahasa, kognisi, psikomotor, nilai moral dan agama (Rozana \& Bantali, 2020). Melihat dari tahapan perkembangan, pengembangaan karakter demokrasi dapat diberikan pada anak usia lima atau enam tahun, yaitu usia TK.

Berdasarkan data pengamatan awal pada 15 Juli 2019, anak-anak dari TK Tut Wuri Handayani Dok VII Kota Jayapura tahun ajaran 2019/2020 menunjukkan bahwa ada yang belum menunjukkan sikap yang mencerminkan karakter demokratis. Pada sampel kelas B2, hasil angket yang dibagikan pada orang tua/wali murid melalui menunjukkan bahwa sebanyak sepuluh anak $(77 \%)$ dari lima belas anak berada pada kategori demokratis yang rendah. Hal ini ditandai dengan belum berkembangnya sikap toleransi, musyawarah, menunjukkan sikap lapang dada, dan menunjukkan sikap tangung jawab. Anak-anak masih mementingkan pendapatnya, ingin menang sendiri, tidak menerima jika ditolak, dan tidak mau mengikuti aturan permainan.

Melihat kesenjangan antara nilai penting karakter demokratis dengan fakta di lapangan, diperlukan rumusan pendidikan karakter demokratis. Kecakapan dan kesadaran pendidik dalam mewujudkan cita-cita yang dimaksud pun sangat berpengaruh untuk membangun anak bangsa dalam memelihara persatuan bangsa. Salah satu pendidik yang berperan penting adalah guru Bimbingan \& Konseling. Pada bidang bimbingan sosial, guru BK membantu siswa menyesuaikan diri yang dilandasi dengan tanggung jawab kewarganegaraan. Hal ini sehubungan dengan pendidikan karakter pada pola pembelajaran integralistik, salah satunya meliputi Pendidikan Kewarganegaraan (Zubaedi, 2015).

Pendidikan yang efektif untuk mempersiapkan warganegara demokratis, mencakup struktur keilmuan pendidikan kewarganegaraan (Damri et al., 2020). (1) Pengetahuan (civic knowledge) tentang prinsip \& proses demokrasi, identitas nasional, masyarakat madani, pemerintahan berdasarkan hukum dan peradilan yang tidak memihak, sejarah nasional, hak dan tanggung-jawab warganegara, hak asasi manusia, hak sipil dan hak politik. (2) Keterampilan (civic skills), meliputi: keterampilan intelektual, keterampilan sosial, keterampilan partisipatif. Keterampilan intelektual, antara lain: berpikir kritis (mengidentifikasi, mendeskripsikan, menganalisis, mengevaluasi, menentukan, dan mempertahankan sikap berkenaan dengan persoalan-persoalan publik). Keterampilan sosial, yaitu menjalankan hak \& tanggungjawab. Keterampilan partisipatif, yaitu keterampilan berinteraksi. (3) Komponen disposisi kewarganegaraan (civic disposition), yaitu memiliki watak pribadi dan kemasyarakatan. Watak pribadi, antara lain: tangggungjawab dan hormat terhadap nilai kemanusiaan. Watak kemasyarakatan, antara lain: semangat kemasyarakatan, hasrat mendengarkan, sopan santun, berfikir kritis, bernegosiasi, berkompromi, dan hormat terhadap peraturan hukum.

Rumusan pendidikan karakter demokratis ini perlu disesuaikan dengan tahapan perkembangan anak-anak. Bilqis et al. (2017) menyebutkan bahwa menghadapi permasalahan anak yang berhubungan dengan bidang sosial, paling cocok adalah menggunakan Group Play Therapy. Hal ini dikarenakan terapi bermain kelompok membuat anak banyak belajar dari proses interaksi dengan teman-temannya dibandingkan hanya dari sebuah teori. Hal ini memunculkan pertanyaan permainan apakah yang cocok untuk meningkatkan karakter demokratis anak TK.

Pada penelitian terdahulu, Nafisah (2016) menggunakan lompat tali \& petak umpet dalam meningkatkan karakter demokratis siswa Sekolah Dasar Kabupaten Pasuruan. Fadlillah (2016) menyebutkan bahwa permainan yang dapat mengembangkan karakter anak, antara lain: permainan puzzle, balok, bak pasir, dan ular naga. Adibatin (2016) menggunakan permainan cincin jempol untuk membangun karakter demokratis. Fath (2016) menggunakan permainan tradisional nogarata to kaili. Fana \& Jatiningsih (2020) menggunakan permainan bekel. Himawan (2020) mengembangkan permainan goteng, lari papan, dan kasti tangan untuk meningkatkan karakter demokrasi anak. Dwi Ervita Masruroh \& Muhibbin (2020) menggunakan audio visual untuk mensosialisasikan nilai-nilai demokrasi. Bahkan, pada penelitian dari database Sagepub yang memuat penelitian Internasional dari seluruh dunia, tidak ada menyebutkan penelitian untuk peningkatan karakter demokratis anak melalui permainan. Hanya saja, Carroll et al. (2019) meneliti anak-anak di Auckland, New Zealand, anak-anak mengklaim hak demokratis mereka atas kota melalui permainan. Artinya, belum ada studi tentang permainan enggo untuk peningkatan karakter demokratis, khususnya di Pulau Papua.

Dalam penelitian Misbach (dalam Syamsurrijal, 2020); Eka Rahmawati \& Mulyadi (2018); dan Ramadhani, (2018) menunjukkan bahwa permainan tradisional dapat menstimulasi berbagai 
aspek perkembangan anak yang meliputi aspek kognitif, motorik, emosi, bahasa, dan sosial. Rizal et al. (2019) menyebutkan bahwa permainan tradisional dapat menjadi media dalam menyampaikan pesan tentang cara mengatasi permasalahan. Oleh sebab itu, dipilihlah permainan tradisional enggo untuk meningkatkan karakter demokratis anak dalam penelitian ini.

Enggo'-enggo' adalah permainan tradisional dari kota Makassar. Enggo'-enggo' dikenal dengan sebutan permainan enggo. Enggo dilakukan oleh tiga orang atau lebih. Peserta permainan berbaris ke belakang. Peserta yang berdiri paling depan memegang sebatang tiang atau pohon menjadi penjaga (Anas, 2018). Penjaga berhitung, sementara pemain lainnya bersembunyi. Ketika hitungan selesai, penjaga mencari pemain lain.

Rumusan masalah penelitian ini, yaitu: 1. Bagaimana langkah-langkah pelaksanaan Traditional Enggo Group Play Therapy untuk meningkatkan karakter demokratis anak? 2. Bagaimana peningkatan karakter demokratis anak dengan diterapkannya Traditional Enggo Group Play Therapy? Tujuan penelitian ini menjelaskan langkah-langkah Traditional Enggo Group Play Therapy untuk peningkatan karakter demokratis anak usia TK dan untuk menjabarkan hasil peningkatan karakter demokratis anak usia TK melalui Traditional Enggo Group Play Therapy.

Manfaat penelitian diharapkan dirasakan bagi siswa, bagi guru, bagi pendidikan dasar, bagi bangsa, dan bagi pengembangan ilmu pengetahuan. Bagi siswa, penelitian ini bermanfaat meningkatkan karakter demokratis dan pembimbingan ini menjadi bekal bagi individu tersebut agar lebih mudah dalam menghadapi persoalan-persoalan di masa depan. Bagi guru, penelitian diharapkan mendapat kemudahan dalam menerapkan pendidikan karakter demokratis pada anak. Bagi pendidikan dasar, diharapkan mencetak generasi yang unggul. Bagi bangsa, penelitian ini diharapkan berkontribusi menyumbangkan calon penerus yang berkarakter demokratis. Bagi ilmu pengetahuan, khususnya bidang Bimbingan dan Konseling, dapat menambah wawasan bahwa permainan tradisional enggo dapat meningkatkan karakter demokratis anak usia dini.

Berdasarkan pemaparan latar belakang di atas, disusun hipotesis tindakan dalam penelitian ini, yaitu: "Traditional Enggo Group Play Therapy dapat meningkatkan karakter demokratis anak TK B2 Tut Wuri Handayani Dok VII Kota Jayapura tahun ajaran 2019/2020."

\section{Metode}

Metode penelitian ini adalah participatory action research (Creswell, 2018). Populasi penelitian berjumlah tujuh puluh lima anak. Penelitian dilaksanakan di TK Tut Wuri Handayani Dok VII Kota Jayapura. TK ini terdiri dari lima kelas. Kelompok A satu kelas, sedangkan kelompok $\mathrm{B}$ empat kelas. Masing-masing kelas terdiri dari lima belas anak. Jumlah subjek penelitian yang dilibatkan adalah anak lima belas siswa TK. Metode sampling penelitian ini adalah teknik purposif, yaitu memiliki semua siswa kelas B2.

Instrumen yang digunakan adalah pedoman observasi, angket karakter demokratis yang diberikan pada orang tua/ wali murid untuk mengetahui karakter demokrasi anaknya selama di rumah, catatan lapangan, wawancara kepada siswa, orang tua/wali murid dan guru, serta dokumentasi. Instrumen tersebut dijelaskan dalam Tabel 1. Instrumen Penelitian. Bentuk pemaparan tabel instrumen penelitian ini menyadur dan memodifikasi dari contoh kisi-kisi instrumen penelitian tindakan Rahmat (2016). Berikut ini Tabel 1. Instrumen Penelitian.

Tabel 1. Instrumen Penelitian

\begin{tabular}{|c|c|c|c|}
\hline Indikator Keberhasilan & & Data & $\begin{array}{l}\text { Alat } \\
\text { data }\end{array}$ \\
\hline \multicolumn{4}{|l|}{ Proses } \\
\hline $\begin{array}{l}\text { Guru BK melakukan } \\
\text { pelaksanaan tindakan }\end{array}$ & prosedur & Pelaksanaan kegiatan & $\begin{array}{l}\text { Pedoman } \\
\text { observasi }\end{array}$ \\
\hline $\begin{array}{l}\text { 1. Siswa mendengarkan guru } \\
\text { penjelasan }\end{array}$ & memberi & $\begin{array}{l}\text { 1. Frekuensi mendengarkan } \\
\text { guru } \\
\text { 2. Menyebut nama teman }\end{array}$ & $\begin{array}{l}\text { 1. Pedoman } \\
\text { observasi }\end{array}$ \\
\hline
\end{tabular}




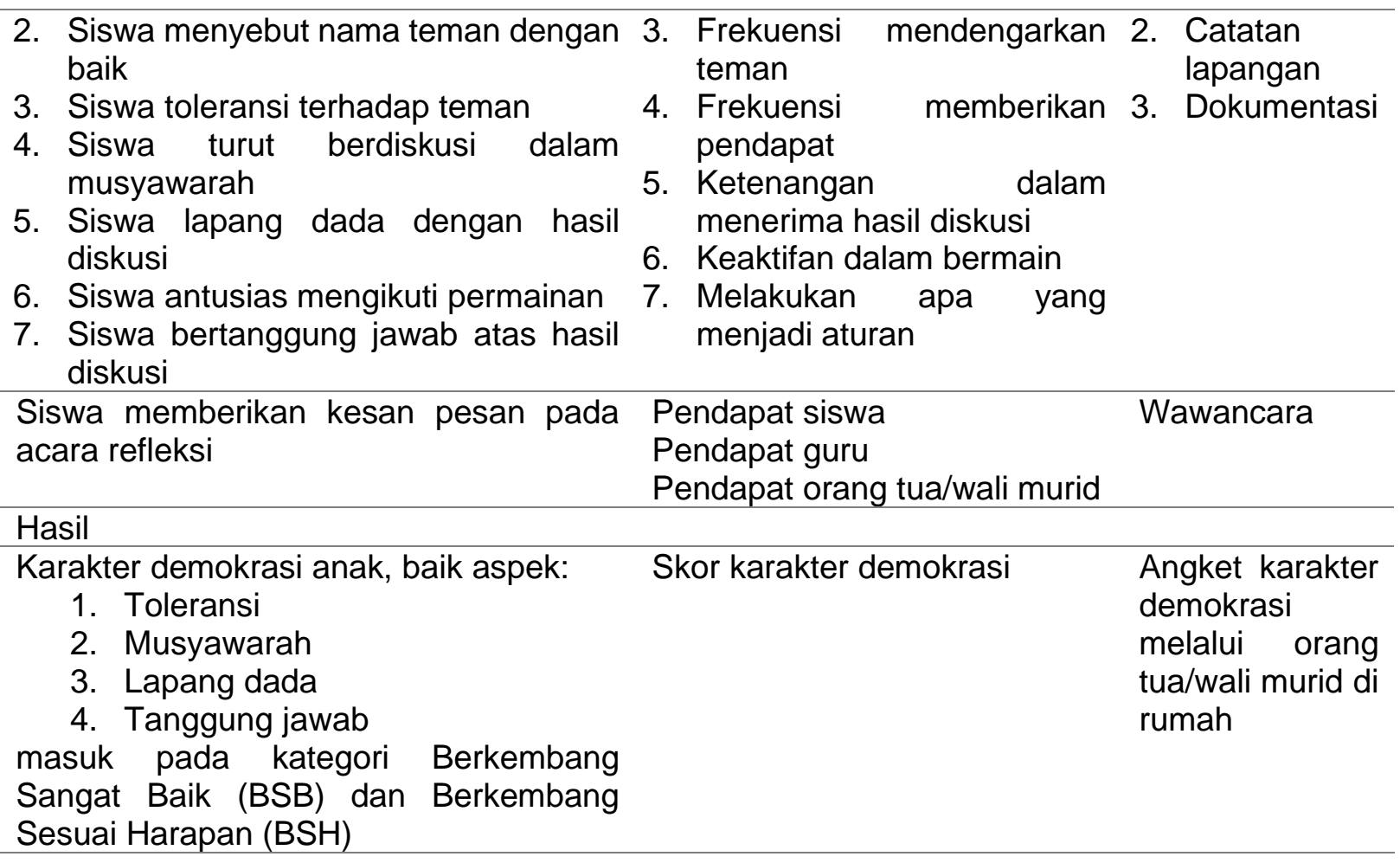

Berdasarkan tabel 1 di atas, tampak bahwa observasi, angket, dan wawancara memiliki pedoman. Instrumen juga dilengkapi dengan analisis dari catatan lapangan dan dokumentasi. Uji validitas instrumen menggunakan metode triangulasi data dengan menggunakan sumber data dari berbagai suasana waktu dan tempat. Sementara itu, pendekatan yang digunakan untuk uji reliabilitas adalah menggunakan practical reliability (Suharsimi \& Suhardjono, 2017).

Prosedur penelitian terdiri dari persiapan, pelaksanaan, hingga penyusunan laporan penelitian. Penelitian dimulai dari akhir Juni 2019 hingga awal Januari 2021. Tahap persiapan dibutuhkan waktu kurang lebih dua bulan. Tahap pelaksanaan di lapangan dibagi menjadi dua siklus. Siklus I \& II masing-masing terdiri dari tiga pertemuan. Tahap pelaksanaan di lapangan dibutuhkan waktu kurang lebih 2,5 bulan sejak 2 September 2019 hingga 18 November 2019. Terakhir, tahap penyusunan laporan penelitian disusun mulai akhir tahun 2019, disusul dengan penyusunan artikel kurang lebih sampai awal tahun 2021. Total lamanya penelitian ini membutuhkan waktu kurang lebih satu setengah tahun.

Peralatan penelitian, antara lain: buku catatan dan bolpoin, jam tangan, dan hadiah untuk anak-anak di kelas yang turut berpartisipasi. Bahan penunjang penelitian yang digunakan, antara lain: kajian literatur, materi peningkatan karakter demokrasi, angket karakter demokrasi, pedoman observasi, dan pedoman wawancara. Analisis data penelitian menggunakan statistik deskriptif (Creswell, 2018).

Batasan metode penelitian ini adalah, penelitian ini menggunakan action research. Kelemahan dari action research adalah hasil penelitian tidak dapat digeneralisasikan pada seluruh anak usia dini, tetapi hanya dikenakan pada siswa kelompok B2 tahun ajaran 2019/2020. Selain itu, materi dan permainan yang disampaikan adalah berfokus pada peningkatan karakter demokrasi anak menggunakan permainan enggo. 


\section{Hasil dan Diskusi}

Hasil penelitian menjawab dua rumusan masalah. Pertama, pemaparan langkah-langkah pelaksanaan Traditional Enggo Group Play Therapy. Kedua, pemaparan peningkatan karakter demokratis anak setelah intervensi.

Berikut ini dijelaskan langkah-langkah pelaksanaan Traditional Enggo Group Play Therapy. Siklus ke-I dan ke-Il dijelaskan dalam Tabel 2. Pelaksanaan Traditional Enggo Group Play Therapy.

Tabel 2. Pelaksanaan Traditional Enggo Group Play Therapy

\section{Siklus ke-}

\begin{tabular}{ll}
\hline Perencanaan & 1. Menyusun rencana awal PTK pada $24 / 6 / 19-1 / 7 / 19$ \\
& 2. Komunikasi ke kepala sekolah pada $8 / 7 / 19$ \\
3. Studi pendahuluan pada $15 / 7 / 19$ \\
4. Menyusun rencana rinci pada $22 / 7 / 19$ \\
5. Menyusun instrumen $29 / 7 / 19-19 / 8 / 19$ \\
6. Persiapan materi, alat, dan bahan pada $26 / 8 / 19$ \\
\hline
\end{tabular}

Pertemuan 1 Tindakan pada 2/9/19

1. Penanaman nilai semangat main bersama teman yang rukun

2. Memilih para pemain

3. Memotivasi kelompok

4. Menentukan aturan-aturan permainan

5. Menemukan lokasi yang cocok

6. Main enggo tahap inti (lebih jelasnya disebutkan di paragraf bawah)

7. Mengingatkan nilai-nilai demokratis

Pengamatan pada $9 / 9 / 19$

Pertemuan 2 Tindakan pada 16/9/19

1. Penanaman nilai toleransi, memberi salam, menyebut nama teman, sopan santun, dan menghargai

Pengamatan pada 23/9/19

Pertemuan 3 Tindakan pada 30/9/19

1. Memahami gambar emosi

2. Belajar mengenali emosi diri \& emosi teman

3. Belajar menghargai emosi diri dan teman

Pengamatan pada $30 / 9 / 19$

Refleksi Pada 30/9/19

1. Siswa memberikan kesan senang/ tidak terhadap proses \& alasannya. Siswa senang karena mendapat pengalaman baru \& memberikan usulan.

2. Penyebaran angket kepada orang tua untuk menilai karakteristik demokratis anak di rumah.

\section{Siklus ke-II}

Perencanaan Pada 7/10/19 Hasil siklus I. Aspek keberhasilan dan kekurangan tindakan pada hasil evaluasi, dicari faktornya berdasar teori dan fakta. Evaluasi tersebut dijadikan landasan dalam memperbaiki siklus I \& merancang tindakan siklus II.

Pertemuan 4 Tindakan pada 14/10/19

1. Penanaman nilai musyawarah dan lapang dada. Menyampaikan pada pertemuan berikutnya akan ada pembagian tugas bersih-bersih kelas sebagai bagian dari tanggung jawab bersama. Ketika terjadi perbedaan pendapat dengan orang lain atau teman, pertama memahami apa yang diinginkan diri. Kemudian, mendengarkan keinginan teman. Lalu, menyampaikan pendapat bersama-sama (diskusi) untuk menemukan titik tengah (negosiasi). Hasil suara terbanyak harus diterima dengan lapang dada.

2. Orang tua/wali murid diberikan materi pola asuh demokratis sebagai bekal pendidikan anak di rumah. 


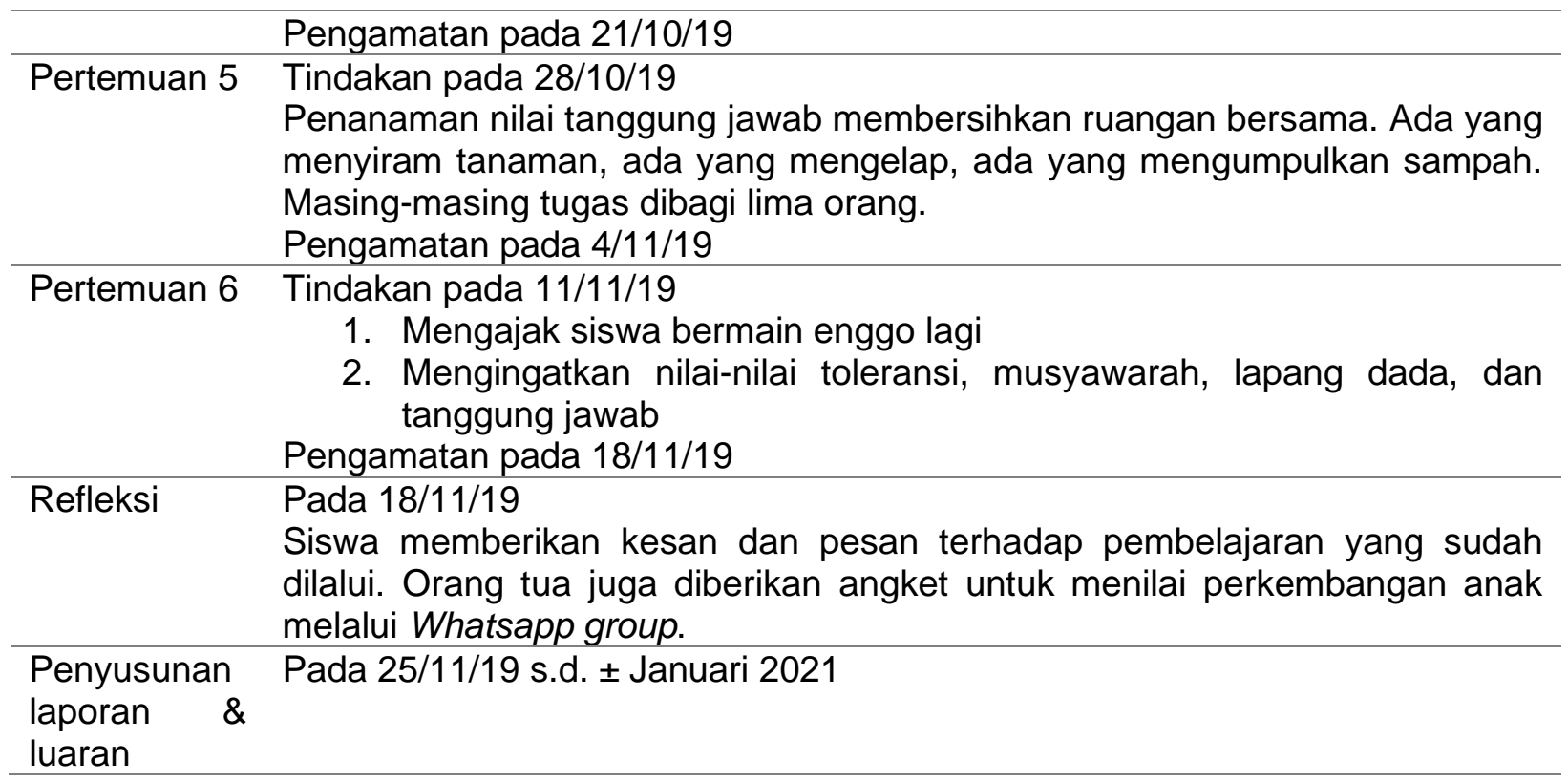

Proses inti bermain enggo menurut (Genggong, 2018), diperankan lebih dari dua pemain. Satu anak menjadi penjaga enggo. Penjaga menutup mata sambil menghitung. Sementar itu, pemain lain berlari mencari tempat untuk bersembunyi. Penjaga harus bermain sambil bernyanyi. Ada lirik khusus yang harus dinyanyikan oleh penjaga. Lirik tersebut dijelaskan sebagai berikut. "Satu cari tempat, dua bersembunyi, tiga berhitung. Satu, dua, tiga, empat, lima, ...(menghitung sampai batas yang ditentukan)." Setelah selesai menghitung, penjaga mencari pemain lain. Jika penjaga menemukan salah satu, maka anak-anak berteriak "Enggo!" Lalu, pemain tersebut keluar dari tempatnya bersembunyi. Namun, ia belum kalah. Anak-anak masih bisa berlari ke enggo dan menyentuh tiang yang telah disepakati sambil berteriak "Enggo!" sebelum si penjaga sampai di sana. Siapa yang tidak bisa menyentuh enggo atau tiang lebih dulu, ia kalah dan menjadi penjaga.

Proses bermain enggo selama penelitian tindakan ini dilakukan didokumentasikan pada Gambar 1. Proses Bermain Enggo berikut.

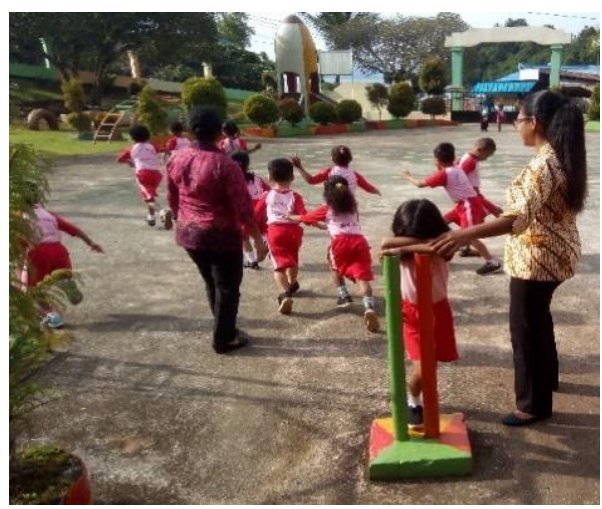

Gambar 1. Proses Bermain Enggo

Gambar di atas menunjukkan pemain penjaga enggo sedang berdiri di depan tiang sambil menutup mata. Sambil penjaga berhitung, teman-teman pemain lainnya berlari bersembunyi. Gambar ini menjadi salah satu alat instrumen dokumentasi penelitian.

Tujuan kedua penelitian ini, terkait pemaparan peningkatan karakter demokratis anak, dianalisis menggunakan 1) pedoman observasi, 2) angket, 3) catatan lapangan, dan juga 4) wawancara. Data dari pedoman observasi kegiatan guru BK didapatkan dari pelaksanaan kegiatan yang telah disebutkan di atas. Pelaksanaan kegiatan tersebut telah dilakukan dengan baik oleh guru BK. 
Analisis peningkatan karakter demokratis berdasarkan pedoman observasi juga ditujukan untuk mengamati perilaku siswa. Tabel 3. Hasil Peningkatan Karakter Demokratis Berdasarkan Observasi sebagai berikut.

Tabel 3. Hasil Peningkatan Karakter Demokratis Berdasarkan Observasi

No. Indikator Pertemuan

\begin{tabular}{lllllllll} 
& & Pra & 1 & 2 & 3 & 4 & 5 & 6 \\
\hline 1 & Siswa mendengarkan guru memberi penjelasan & $\vee$ & $\vee$ & $\vee$ & $X$ & $\vee$ & $X$ & $V$ \\
\hline 2 & Siswa menyebut nama teman dengan baik & $\mathrm{X}$ & $\vee$ & $\vee$ & $X$ & $\vee$ & $\vee$ & $\vee$ \\
\hline 3 & Siswa toleransi terhadap teman & $\mathrm{X}$ & $\mathrm{X}$ & $\mathrm{X}$ & $\vee$ & $\vee$ & $\vee$ & $\vee$ \\
\hline 4 & Siswa turut berdiskusi dalam musyawarah & $\mathrm{X}$ & $\mathrm{X}$ & $\vee$ & $\vee$ & $\vee$ & $\vee$ & $\vee$ \\
\hline 5 & Siswa lapang dada dengan hasil diskusi & $\mathrm{X}$ & $\mathrm{X}$ & $\mathrm{X}$ & $\vee$ & $\mathrm{X}$ & $\vee$ & $\vee$ \\
\hline 6 & Siswa antusias mengikuti permainan & $\vee$ & $\vee$ & $\vee$ & $\vee$ & $\vee$ & $\vee$ & $\vee$ \\
\hline 7 & Siswa bertanggung jawab atas hasil diskusi & $\mathrm{X}$ & $\mathrm{X}$ & $\mathrm{X}$ & $\vee$ & $\vee$ & $\vee$ & $\vee$ \\
\hline & Total & 2 & 3 & 4 & 5 & 6 & 6 & 7
\end{tabular}

Keterangan: $(\mathrm{V})=$ lya; $(\mathrm{X})$ = Tidak

Observasi sebelum tindakan menunjukkan bahwa ada lima dari delapan indikator menunjukkan respon anak secara umum dari kelas TK B2 belum mencapai karakter demokratis. Pada tindakan pertemuan pertama hingga terakhir menunjukkan adanya peningkatan skor yang dinamis, mulai dari dua hingga sempurna. Terdapat item-item yang awalnya indikator tercapai dengan baik, kemudian turun di minggu berikutnya. Pada pertemuan terakhir, yaitu pertemuan enam, menunjukkan bahwa siswa TK B2 telah memenuhi semua indikator karakter demokratis. Sebagai contoh, pada pertemuan kedua, ditemukan bahwa siswa mendengarkan guru, tetapi tidak pada pertemuan tiga dan lima. Hal ini wajar karena di lapangan terdapat dinamika proses, apakah anak merasa bosan, atau merasa ingin bermain lagi. Ketika disinkronkan dengan hasil wawancara, ternyata anak tidak tahan diam lama. Oleh karena itu, ini menjadi evaluasi bagi guru BK atau peneliti. Positifnya, pada pertemuan keempat dan terakhir, anak-anak di kelas mampu mengengarkan guru dengan baik.

Contoh lain, pada pertemuan kedua, siswa menyebut nama teman dengan baik, tetapi tidak pada pertemuan ketiga, karena terdapat konflik. Ada anak-anak yang konfrontasi terhadap kelompok lain karena teman satu kelompok tidak pernah berganti pada hari berikutnya. Meski ada canda ada tawa, ada juga ketegangan emosional. Hal ini tentu tetap dipantau oleh guru dan peneliti dalam rangka mengarahkan dan membimbing kepada sikap demokrasi.

Konflik ini adalah sebuah proses siswa belajar. Guru dan peneliti menyampaikan poinpoin positif dari konflik dan solusi permasalahan dalam permainan ini. Persepsi yang positif akan mempengaruhi sikap positif siswa dalam menghadapi konflik interpersonal (Bilqis, 2013). Pada pertemuan keempat dan keenam, susunan kelompok diubah. Hasil observasi menunjukkan siswa menyebutkan teman dengan baik, sopan, santun, dan saling menghormati.

Satu contoh lagi, dalam aspek lapang dada, pertemuan ketiga, anak sudah menunjukkan sikap lapang dada. Akan tetapi, hal ini tidak tampak pada pertemuan keempat karena ada salah satu siswa yang tidak mau pendapatnya dikalahkan. Namun, pada pertemuan kelima dan terakhir, siswa di kelas sudah mampu menunjukkan kemajuan dalam lapang dada. Inilah dinamika penelitian di lapangan, perilaku bisa naik turun (Diniaty, 2018). Karena itu, minimal penelitian tindakan dibutuhkan dua siklus, setiap siklus minimal tiga pertemuan (Suharsimi \& Suhardjono, 2017). Hal ini bertujuan supaya karakter baru lebih terinternalisasi dan hasil pengamatan dapat lebih valid. 
Berdasarkan hasil angket karakter demokrasi yang diberikan kepada orang tua/wali murid siswa dari pra penelitian, siklus I, dan siklus II, didapatkan data peningkatan siswa yang memiliki karakter demokrasi. Berikut ini Gambar 2. Peningkatan Karakter Demokrasi Kelas B2 TK Tut Wuri Handayani Dok VII Jayapura.

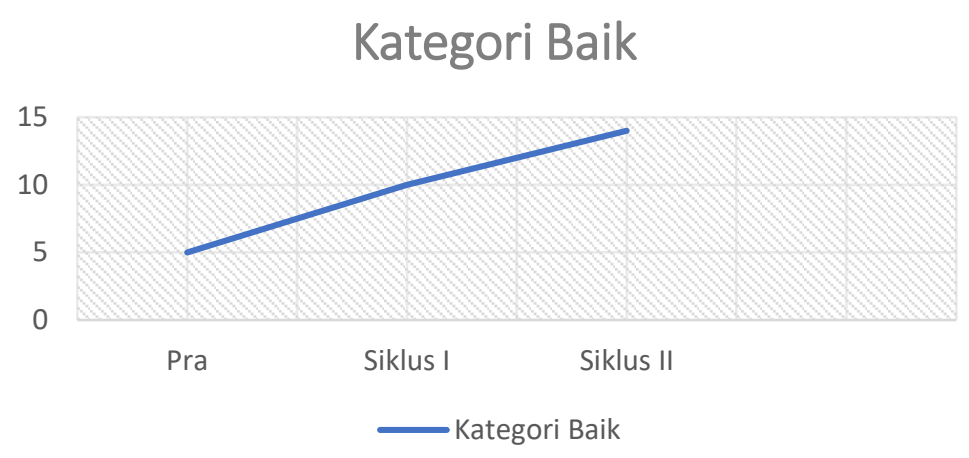

Gambar 2. Peningkatan Karakter Demokrasi Kelas B2 TK Tut Wuri Handayani Dok VII Jayapura

Gambar 2 di atas menunjukkan bahwa sebelum dilakukan tindakan, sebanyak lima anak atau $33 \%$ dari lima belas anak pada kategori baik. Setelah siklus I, kategori baik menjadi sepuluh anak atau $67 \%$ dari lima belas anak. Setelah siklus II, meningkat menjadi empat belas anak atau 93\% dari lima belas anak yang masuk kategori baik.

Hasil angket karakter demokrasi yang dibagikan kepada orang tua/wali murid untuk menilai anaknya di rumah secara umum menunjukkan bahwa anak berada pada kategori tinggi. Hal ini ditampilkan dalam Tabel 4. Distribusi Skor Aspek Karakter Demokratis Kelas B2 TK Tut Wuri Handayani Dok VII Kota Jayapura sebagai berikut.

Tabel 4. Distribusi Skor Aspek Karakter Demokratis Kelas B2 TK Tut Wuri Handayani Dok VII Jayapura

\begin{tabular}{llllllllllll}
\hline No & Aspek & \multicolumn{2}{c}{ BSB } & BSH & \multicolumn{3}{c}{ MB } & \multicolumn{2}{c}{ BB } & \multicolumn{2}{c}{ TOTAL } \\
\cline { 2 - 11 } & $\mathrm{F}$ & $\%$ & $\mathrm{~F}$ & $\%$ & $\mathrm{~F}$ & $\%$ & $\mathrm{~F}$ & $\%$ & $\mathrm{~F}$ & $\%$ \\
\hline 1 & $\begin{array}{l}\text { Menunjukkan sikap } \\
\text { toleransi }\end{array}$ & 6 & 40 & 9 & 60 & 0 & 0 & 0 & 0 & 15 & 100 \\
\hline 2 & $\begin{array}{l}\text { Menunjukkan sikap } \\
\text { musyawarah }\end{array}$ & 0 & 0 & 14 & 93 & 1 & 7 & 0 & 0 & 15 & 100 \\
\hline 3 & $\begin{array}{l}\text { Menunjukkan sikap } \\
\text { lapang dada }\end{array}$ & 13 & 13 & 87 & 0 & 0 & 0 & 0 & 15 & 100 \\
\hline 4 & $\begin{array}{l}\text { Menunjukkan sikap } \\
\text { tanggung jawab }\end{array}$ & 3 & 20 & 12 & 80 & 0 & 0 & 0 & 0 & 15 & 100 \\
\hline
\end{tabular}

Keterangan: $\mathrm{F}=$ Frekuensi; $\mathrm{BSB}=$ Berkembang Sangat Baik; BSH = Berkembang Sesuai Harapan; $\mathrm{MB}=$ Mulai Berkembang; dan $\mathrm{BB}=$ Belum Berkembang

Berdasarkan Tabel 4 tampak bahwa pada setiap dimensi mayoritas siswa berada pada kategori BSH (60\% siswa pada kategori toleransi, 93\% siswa pada kategori musyawarah, $87 \%$ pada kategori lapang dada, dan $80 \%$ pada kategori tanggung jawab). Sisanya berada pada kategori BSB (40\% toleransi, 13\% lapang dada, 20\% tanggung jawab). Hanya sedikit siswa yang kategorinya tinggi (7\% siswa pada dimensi musyawarah). Tidak ada lagi siswa yang berada pada kategori aspek karakter demokratis yang rendah.

Untuk aspek toleransi, yang dinyatakan tuntas dalam pembelajaran adalah anak yang termasuk Berkembang Sangat Baik (BSB) dan kategori Berkembang Sesuai Harapan (BSH) sebanyak 15 anak atau 100\%. Untuk aspek musyawarah, anak yang dinyatakan tuntas dalam pembelajaran adalah kategori BSB dan BSH sebanyak 14 anak atau 93\%. Untuk aspek lapang dada, anak yang tuntas dalam pembelajaran dalam kategori BSB dan BSH sebanyak 15 anak atau $100 \%$. Untuk aspek tanggung jawab, anak yang dinyatakan tuntas dalam kategori BSB dan BSH sebanyak 15 orang atau $100 \%$. Jadi, semua anak dari hasil angket, kecuali satu anak dalam dimensi musyawarah, dinyatakan tuntas telah Berkembang Sangat Baik dan Berkembang Sesuai Harapan pada karakter demokratis. 
Meski terdapat satu siswa yang aspek sikap musyawarahnya Mulai Berkembang (MB), siswa tersebut telah menunjukkan peningkatan. Sebelumnya, siswa tersebut sulit sekali untuk mau mendengarkan teman dan individualis. Hal ini dibenarkan oleh orang tua/wali murid siswa tersebut. Hal ini menunjukkan bahwa terdapat peningkatan karakter demokrasi pada anak kelas B2 TK Tut Wuri Handayani Dok VII Kota Jayapura.

Data dari catatan lapangan, diuraikan sebagai berikut. Anak-anak sangat antusias menyambut metode belajar permainan enggo dengan tidak sabaran ingin cepat-cepat bermain meskipun masih dalam tahap penjelasan aturan main. Bahkan, ada siswa yang sudah saling mengajak untuk berkelompok bermain enggo segera. Motivasi anak-anak sangat baik dengan metode permainan enggo. Ada anak yang sedang dan telah merencanakan tempat-tempat persembunyian yang handal menurut anak-anak. Ada yang mencoba mengusulkan kepada guru dan peneliti dalam rangka memilih teman sekelompok.

Gambaran kondisi kelas pada saat sebelum dilakukan tindakan adalah sebagai berikut. Sikap demokratis masih rendah pada setiap pola anak, khususnya anak laki-laki. Hal ini ditandai dengan sikap anak yang belum mampu berbaur dengan teman lain, masih suka membedakan teman waktu bermain. Pada aspek tanggung jawab, anak belum mampu patuh pada aturan permainan enggo. Anak-anak belum tertib pada waktu bermain enggo. Anak belum mampu bersikap tanggung jawab selama menjaga benteng atau sembunyi.

Anak laki-laki cenderung memiliki karakteristik yang lebih mendominasi dan tidak mau kalah dibandingkan anak perempuan (Kristanto, 2016). Karena itu, sikap demokrasi pada sebelum tindakan muncul sangat kurang pada siswa khususnya siswa berjenis kelamin laki-laki. Pada anak usia lima tahun di jenjang TK 0 kecil, persahabatan didasarkan pada aktivitas bersama. Mulai jenjang TK 0 besar, pada usia enam tahun, persahabatan terbangun lebih karena adanya kesamaan fisik dan kepercayaan timbal balik (Wulandari \& Rahmi, 2018).

Gambaran kondisi kelas setelah dilakukan tindakan menunjukkan perubahan-perubahan yang positif. Setelah siklus dua, anak-anak sudah mampu menunjukkan sikap toleransi, musyawarah, lapang dada, dan tanggung jawab. Anak-anak tampak memberikan minat yang positif terhadap teman. Anak-anak terlihat lebih disiplin terhadap aturan main. Beberapa anak menunjukkan sikap mengayomi teman-teman dalam permainan dan memberi saran bagi teman lain untuk diam, tenang, serta waspada saat bersembunyi.

Ada perbedaan antara pembelajaran biasa dengan model pembelajaran selama penelitian tindakan ini. Selama model pembelajaran diterapkan, anak-anak tampak lebih mudah diatur. Sesudah menjalankan Group Play Therapy, anak-anak menjadi lebih perhatian dan menghargai teman. Suasana kelas menjadi lebih hangat dan akrab. Guru nampak lebih bersemangat untuk mendorong anak bermain karena mengetahui bahwa bermain adalah bentuk terapi. Selain itu, peneliti juga merasa ada peningkatan keterampilan pengelolaan kelas.

Berdasarkan hasil wawancara, didapatkan kumpulan data dari siswa, guru, dan orang tua/wali murid. Hasil wawancara kepada siswa ketika proses refleksi siklus I \& II. Pada siklus I, siswa menyatakan bahwa mereka merasa senang terhadap proses, tetapi juga ada yang tidak suka. Hal ini dikarenakan ada teman yang di awal-awal tampak mementingkan diri sendiri. Siswa memberikan usulan agar temannya melindungi benteng pertahanannya. Pada siklus II, siswa mengatakan bahwa sangat senang dan puas selama proses bermain enggo dan belajar. Mereka merasa bahwa teman-teman sudah tidak lagi memilih-milih dalam berteman, merasa seperti menjadi semakin dekat satu sama lain.

Hasil wawancara terhadap guru, ditemukan fakta bahwa sesudah menjalankan Group Play Therapy, guru merasa senang mendapat referensi baru model Group Play Therapy. Anak TK memang proses belajarnya adalah dari hasil bermain. Group Play Therapy membuat anak mendapat proses belajar bersosial secara langsung, dibandingkan hanya dengan teori (Sweeney et al., 2014).

Hasil wawancara terhadap orang tua/wali murid menunjukkan bahwa mereka merasa konflik dengan anak berkurang. Gaya anak berbicara menjadi lebih bijaksana dan dewasa. Pendidikan untuk membangun karakter demokratis anak bisa dibutuhkan koordinasi dengan orang tua agar dalam pengasuhan memberi contoh pengasuhan dengan pola asuh demokratis (Tridonanto, 2014). 
Karena Traditional Enggo Group Play Therapy dapat meningkatkan karakter demokratis anak. Hipotesis tindakan yang berbunyi: "Traditional Enggo Group Play Therapy dapat meningkatkan karakter demokratis anak TK B2 Tut Wuri Handayani Dok VII Kota Jayapura tahun ajaran 2019/2020" dinyatakan diterima. Temuan penelitian ini memperkuat temuan Misbach (dalam Syamsurrijal, 2020); Eka Rahmawati \& Mulyadi (2018); Ramadhani, (2018); dan Rizal et al. (2019) bahwa permainan tradisional dapat digunakan untuk menstimulasi kemampuan sosial anak. Temuan penelitian ini juga melengkapi temuan penelitian sebelumnya tentang manfaat Group Play Therapy, antara lain: masalah perilaku (Sarihi et al., 2015), oppositional defiant children (Morshed et al., 2015), daya tarik interpersonal (Bilqis et al., 2017), kecemasan, depresi, dan penyesuaian diri (Swan et al., 2019), perilaku agresi (Ajallooeian et al., 2015); (Badamian \& Ebrahimi Moghaddam, 2017), kecemasan dan masalah perilaku (Swan et al., 2019), kecemasan (Heshmati et al., 2016); (Davidson et al., 2017), dan komunikasi anak autis (Rafati et al., 2016). Traditional Enggo Group Play Therapy dapat dicatat dalam tulisan ilmiah, bahwa terapi ini mampu meningkatkan karakter demokratis anak juga.

Penyebab mengapa terdapat peningkatan karakter demokratis setelah dilakukan tindakan dijelaskan sebagai berikut. Traditional Enggo Group Play Therapy merupakan metode pembelajaran tematik yang tergolong baru diterapkan. Proses pembelajaran bermain enggo yang baru, menarik dan menyenangkan menjadikan anak-anak semangat, antusias, dan fokus dalam pembelajaran. Hal ini mendukung anak-anak berproses untuk membentuk karakter demokratis yang optimal.

Terdapat proses belajar anak untuk membentuk karakter demokratis selama bermain enggo. Semua anak terlihat menikmati dan bahagia dalam memainkan permainan enggo. Ada situasi kekompakkan dalam group. Ada situasi konfrontasi antar anak. Ada diskusi-diskusi kecil antar anak. Ada sikap pemahaman antar anak dan kelompok bermain enggo. Ada kejujuran dan keterbukaan antar kelompok bermain enggo. Ada terlihat proses sikap kesetiakawanan. Bahkan, di akhir permainan enggo anak-anak saling berjabat tangan. Ada juga yang berpelukan polos penuh kasih sambil tertawa. Hal tersebutlah yang menjadi indikator meningkatnya karakter demokrasi.

Kemudian, langkah evaluasi dan tindak lanjut permainan enggo, mengembangkan situasi permasalahan yang dirasakan oleh anak-anak ke arah karakter demokrasi. Permasalahan yang terjadi saat berlangsungnya permainan enggo menjadi salah satu lahan yang subur dalam hati nurani anak-anak untuk disemaikan benih-benih karakter demokrasi. Proses penanaman karakter demokrasi berlangsung secara emosional dan natural.

Dengan demikian, permainan enggo memberikan manfaat-manfaat bagi anak-anak. Berikut beberapa manfaat permainan enggo bagi anak-anak (Aini, 2020), antara lain: (1) menyenangkan; (2) bersosialisasi, karena setiap anak terlibat interaksi; (3) membuat anak aktif bergerak untuk pertumbuhan motorik saat anak berlari dan bersembunyi; (4) belajar menghafal hitungan; (5) melatih sportivitas bagi pemain yang kalah menjadi penjaga; (6) melatih kreativitas untuk bersembunyi tanpa diketahui pemain penjaga; (7) membentuk karakter demokrasi, karena pemain membuat kesepakatan aturan permainan; (8) belajar taat aturan agar permainan tetap menyenangkan.

Keterbatasan hasil penelitian ini adalah ruang lingkup penelitian adalah siswa kelompok B2 Taman Kanak-kanak Tut Wuri Handayani Dok VII Jayapura tahun ajaran 2019/2020 yang berjumlah hanya lima belas anak. Hasil penelitian dapat berbeda apabila dilakukan dalam setting jenjang pendidikan, wilayah, dan tahun yang berbeda. Hasil penelitian bisa berubah seiring proses belajar dan tumbuh berkembang anak.

Saran penelitian lanjutan adalah permainan tradisional enggo dari daerah Makassar yang digunakan untuk menumbuhkan karakter demokrasi pada anak dapat menginspirasi peneliti lain untuk menerapkan permainan serupa dengan pengembangan tujuan karakter yang berbeda. 


\section{Simpulan}

Traditional Enggo Group Play Therapy dapat meningkatkan karakter demokratis anak TK B2 Tut Wuri Handayani Dok VII Kota Jayapura tahun ajaran 2019/2020, baik dari aspek toleransi, musyawarah, lapang dada, dan tanggung jawab. Jika sejak dini anak sudah memiliki karakter demokratis, maka ketika dewasa diharapkan menjadi generasi penerus bangsa yang berdemokratis. Temuan penelitian ini memperkuat temuan penelitian sebelumnya tentang keefektifan permainan tradisional untuk menstimulasi kemampuan sosial anak, tetapi juga melengkapi karena belum ada penelitian tentang Traditional Enggo Group Play Therapy. Temuan penelitian ini juga melengkapi temuan penelitian sebelumnya tentang manfaat Group Play Therapy terhadap masalah perilaku, symptoms of oppositional defiant, daya tarik interpersonal, kecemasan, depresi, penyesuaian diri, agresi, dan komunikasi. Group Play Therapy dapat dicatat secara ilmiah, mampu meningkatkan karakter demokratis anak juga.

\section{Ucapan Terima Kasih}

Terimakasih kepada Kepala Sekolah, peserta didik, guru, dan orang tua/wali murid di Taman Kanak-kanak Tut Wuri Handayani Dok VII Jayapura atas kerjasamanya dalam penerapan penelitian tindakan ini, sehingga penelitian dapat berjalan dengan lancar.

\section{Daftar Rujukan}

Adibatin, A. (2016). Pendidikan karakter bangsa berbasis strategi pembelajaran pakem melalui permainan cincin di jempol tangan (karya inovasi pembelajaran sekolah dasar). Scholaria: Jurnal Pendidikan Dan Kebudayaan, 6(1), 1-18.

AINI, N. (2020). NILAI-NILAI KARAKTER ISLAMI PADA PERMAINAN TRADISIONAL ANAK DI DESA MUJIRAHAYU KECAMATAN SEPUTIH AGUNG KABUPATEN LAMPUNG TENGAH. UIN Raden Intan Lampung.

Ajallooeian, E., Gorji, Y., \& Niknejadi, F. (2015). Evaluate the Effectiveness of Social Skills Training through Group Therapy Play on Reducing Rational Aggression Boy Elementary School Student in Esfahan City (2013-2014). Journal of Social Sciences and Humanities Research, 3(01), 1-5.

ANAS, A. (2018). Perancangan Ilustrasi Untuk Melestarikan Permainan Tradisional Di Kota Makassar. Universitas Negeri Makassar.

Badamian, R., \& Ebrahimi Moghaddam, N. (2017). The effectiveness of cognitive-behavioral play therapy on flexibility in aggressive children. Journal of Fundamentals of Mental Health, 19(special issue), 133-138.

Bilqis, F. (2013). Hubungan Antara Persepsi Dengan Cara Penyelesaian Konflik Interpersonal Pada Siswa Kelas XI Jurusan Akuntansi SMK Mahardhika. Jurnal BK UNESA, 3(1).

Bilqis, F. (2017). PERBEDAAN KEEFEKTIFAN ANTARA ADLERIAN GROUP PLAY COUNSELING DAN LAYANAN BIMBINGAN KLASIKAL DALAM MENINGKATKAN DAYA TARIK INTERPERSONAL: Penelitian Mix-Method terhadap Siswa Kelas $V$ SDN Sukasenang dan SDN Cihaurgeulis 2 Tahun Ajaran 2016/2017. Universitas Pendidikan Indonesia.

Bilqis, F., Karina, T., \& Latipah, I. C. (2019). Peran konselor dalam mewujudkan sekolah aman dan damai bagi siswa. TERAPUTIK: Jurnal Bimbingan Dan Konseling, 2(3), 115-122.

Bilqis, F., Taufiq, A., \& Saripah, I. (2017). The Effectiveness Differences Of Adlerian Group Play Counseling And Classroom Guidance Activity In Improving Interpersonal Attractiveness. Psikopedagogia Jurnal Bimbingan Dan Konseling, 6(2), 12-19.

Carroll, P., Calder-Dawe, O., Witten, K., \& Asiasiga, L. (2019). A prefigurative politics of play in public places: children claim their democratic right to the city through play. Space and Culture, 22(3), 294-307.

Creswell, J. W. (2018). Educational Research Mylab Education Access Code Includes Pearson 
412 Peningkatan karakter demokratis melalui Traditional Enggo Group Play Therapy pada anak usia TK

Etext: Planning, Conducting, and Evaluating Quantitative and Qualitative Research. Pearson Education. https://books.google.co.id/books?id=ddlOuQEACAAJ

Damri, M. P., Putra, F. E., \& Kom, M. I. (2020). Pendidikan Kewarganegaraan. Prenada Media.

Davidson, B., Satchi, N. S., \& Venkatesan, L. (2017). Effectiveness of play therapy upon anxiety among hospitalised children. International Journal of Advance Research, Ideas and Innovations in Technology, 3(5), 441-444.

Diniaty, A. (2018). DINAMIKA PERUBAHAN DALAM KONSELING: Memahami Permasalahan Klien dan Penanganannya. Kreasi Edukasi.

Dwi Ervita Masruroh, W., \& Muhibbin, A. (2020). Sosialisasi Nilai-Nilai Demokrasi Indonesia Melalui Audio Visual Dan Modifikasi Strategi Small Group Discussion Kolaborasi True Or False Pada Pemuda Karang Taruna Desa Kalimacan Kecamatan Kalijambe Kabupaten Sragen Tahun 2020. Universitas Muhammadiyah Surakarta.

Eka Rahmawati, A., \& Mulyadi, S. H. (2018). Penanaman Karakter Cinta Tanah Air melalui Permainan Tradisional pada Siswa Kelas Tinggi di SDIT Mardhatillah Kemasan. Universitas Muhammadiyah Surakarta.

Fadlillah, M. (2016). Penanaman Nilai-Nilai Karakter Pada Anak Usia Dini Melalui PermainanPermainan Edukatif. Prosiding Seminar Nasional Dan Call for Paper Ke-2 "Pengintegrasian Nilai Karakter Dalam Pembelajaran Kreatif Di Era Masyarakat Ekonomi ASEAN."

Fana, F., \& Jatiningsih, O. (2020). KONTRIBUSI PERMAINAN TRADISIONAL DALAM PEMBENTUKAN KARAKTER DI SDN SIMOKERTO V/138 SURABAYA. Kajian Moral Dan Kewarganegaraan, 8(2).

Fath, S. N. (n.d.). PERMAINAN TRADISIONAL NOGARATA TO KAILI SEBAGAI MEDIA PENDIDIKAN PKn DALAM MEMBANGUN NILAI KARAKTER KEWARGANEGARAAN SISWA SMP NEGERI 13 PALU. EDU CIVIC, 4(1).

Genggong, M. S. (2018). Government role in development of child-friendly city based on traditional games. International Research Journal of Management, IT and Social Sciences, 5(4), 53-60.

HAKIM, S. (2020). DISTORSI HUMANISME DALAM KONSEP ISLAM RAHMATAN LIL'AALAMIIN DI INDONESIA (Studi Internalisasi Humanisme dalam Islam). Al-Afkar, Journal For Islamic Studies, 3(1, January), 1-19.

Harefa, D., \& Fatolosa Hulu, M. M. (2020). Demokrasi Pancasila di Era Kemajemukan. PM Publisher.

Hasanah, N. M. (2019). Penyelenggaraan Jalur Pendidikan Formal dan Nonformal. JECED: Journal of Early Childhood Education and Development, 1(2), 84-97.

Hendayani, M. (2019). Problematika Pengembangan Karakter Peserta Didik Di Era 4.0. Jurnal Penelitian Pendidikan Islam,[SL], 7(2), 183-198.

Heshmati, R., Onari Asl, R., \& Shokrallah, R. (2016). The effectiveness of group play therapy techniques on state anxiety, positive emotions and general compatibility level in special students with learning disabilities. Journal of Learning Disabilities, 5(4), 7-24.

Himawan, F. (2020). Pengembangan Model Pembelajaran Berbasis Aktivitas Jasmani Untuk Karakter Demokratis Tema 2 Subtema 1 Bagi Siswa Kelas IV SDN Bendan Ngisor Semarang. Caruban: Jurnal Ilmiah IImu Pendidikan Dasar, 3(2), 137-145.

Hudayah, C. P., \& Harmanto, H. (2021). PERAN PEMBINA DALAM MEMBANGUN SIKAP DEMOKRATIS BAGI PENGURUS OSIS DI SMKN 1 BUDURAN SIDOARJO. Kajian Moral Dan Kewarganegaraan, 9(1), 1-15.

Humaira, A. (2021). KONSEP NEGARA DEMOKRASI.

Idris, S. (2014). Demokrasi dan Filsafat Pendidikan (Akar Filosofis dan Implikasinya dalam Pengembangan Filsafat Pendidikan). Ar-Raniry Press.

Khoiruddin, M. A. (2018). Perkembangan Anak Ditinjau dari Kemampuan Sosial Emosional. Tribakti: Jurnal Pemikiran Keislaman, 29(2), 425-438.

Kristanto, E. (2016). Perbedaan tingkat kebersyukuran pada laki-laki dan perempuan. Dipresentasikan Pada Seminar ASEAN 2nd Psychology and Humanity, Malang.

Kurnia, I. (2019). KONSEP PENDIDIKAN KARAKTER MENURUT KH AHMAD DAHLAN. IAIN BENGKULU.

Maria, I., \& Amalia, E. R. (2018). Perkembangan Aspek Sosial-Emosional dan Kegiatan 
Pembelajaran yang Sesuai untuk Anak Usia 4-6 Tahun.

Morshed, N., Davoodi, I., \& Babamiri, M. (2015). Effectiveness of group play therapy on symptoms of oppositional defiant among children. J Educ Community Health, 2(3), 12-18.

Mulyono, B. (2017). Reorientasi civic disposition dalam kurikulum Pendidikan Kewarganegaraan sebagai upaya membentuk warga negara yang ideal. Jurnal Civics: Media Kajian Kewarganegaraan, 14(2), 218.

Muslih, M., \& Ulfah, R. A. (2020). URGENSI KARAKTERISTIK WARGANEGARA DEMOKRATIS PADA ABAD KE DUA PULUH SATU. Citizenship Jurnal Pancasila Dan Kewarganegaraan, $7(2), 125-138$.

Nafisah, W. (2016). Pengaruh permainan tradisional petak umpet dan lompat tali terhadap pembentukan karakter demokratis dan disiplin anak usia sekolah dasar di SDN Pakukerto 1 Sukorejo Kabupaten Pasuruan. Universitas Islam Negeri Maulana Malik Ibrahim.

Nasution, T. (2018). Membangun Kemandirian Siswa Melalui Pendidikan Karakter. ljtimaiyah: Jurnal Pendidikan Dan IImu Sosial, 2(1).

Noor, F. (2017). Fenomena Post Democracy Party Di Indonesia: Kajian Atas Latar Belakang, Karakteristik Dan Dampaknya. Jurnal Penelitian Politik, 14(2), 109-126.

Nurmalitasari, F. (2015). Perkembangan sosial emosi pada anak usia prasekolah. Buletin Psikologi, 23(2), 103-111.

Piscarika, M., Afdal Jamil, Z., \& Mukminin, A. (2020). PEMBENTUKAN KARAKTER SISWA MELALUI KEGIATAN KEPRAMUKAAN DI MADRASAH IBTIDAIYAH NEGERI KOTA $J A M B I$. UIN Sulthan Thaha Saifuddin Jambi.

Rafati, F., Pourmohamadreza-Tajrishi, M., Pishyareh, E., Mirzaei, H., \& Biglarian, A. (2016). Effectiveness of group play therapy on the communication of 5-8 years old children with high functioning autism. Archives of Rehabilitation, 17(3), 200-211.

Rahmat, D. (2016). Penelitian tindakan dalam bimbingan dan konseling.

Ramadhan, I. (2021). INDONESIA ADALAH NEGARA DEMOKRASI.

Ramadhani, A. (2018). Identifikasi nilai-nilai pendidikan karakter dalam permainan anak tradisional. Prosiding Seminar Nasional IPTEK Olahraga (SENALOG), 1(1).

Rizal, E., Khadijah, U. L. S., Rejeki, D. S., Hadian, S. M., \& Anwar, R. K. (2019). Traditional Game As The Communication Media In Delivering Message About How To Resolve The Disaster. 1st International Conference on Life, Innovation, Change and Knowledge (ICLICK 2018), 166-170.

Rosyad, A. M., \& Maarif, M. A. (2020). Paradigma Pendidikan Demokrasi Dan Pendidikan Islam Dalam Menghadapi Tantangan Globalisasi Di Indonesia. Nazhruna: Jurnal Pendidikan Islam, 3(1), 75-99.

Rozana, S., \& Bantali, A. (2020). STIMULASI PERKEMBANGAN ANAK USIA DINI: MELALUI PERMAINAN TRADISIONAL ENGKLEK. EDU PUBLISHER.

Sa'idi, R. (2017). Urgensi menjaga kemajemukan dan toleransi dalam era demokrasi. Jurnal Tapis: Jurnal Teropong Aspirasi Politik Islam, 13(2), 74-90.

Sajadi, D. (2019). Pendidikan karakter dalam perspektif Islam. Tahdzib Al-Akhlaq: Jurnal Pendidikan Islam, 2(2), 16-34.

Sarihi, N., Pournesaei, G. S., \& Nikakhlagh, M. (2015). Effectiveness of group play therapy on behavior problems in preschool children. Journal of Analytical-Cognitive Psychology, 6(23), $35-41$.

Saripah, I., \& Bilqis, F. (2019). Pengembangan program Adlerian group play counseling untuk meningkatkan daya tarik interpersonal siswa kelas V Sekolah Dasar. TERAPUTIK: Jurnal Bimbingan Dan Konseling, 2(3), 141-155.

Setiawati, E., Bahri, A. S., Firmadani, F., Safari, M., Pramanik, P. D., Nuramila, N., Rahmah, R. E., Nuryanti, N., Pratama, A. Y., \& Nurmiyanti, L. (2020). Pendidikan Karakter.

Suharsimi, A., \& Suhardjono, S. (2017). Penelitian Tindakan Kelas (Edisi Revisi). PT Bumi Askara, Jakarta.

Sulaiman, U., Ardianti, N., \& Selviana, S. (2019). TINGKAT PENCAPAIAN PADA ASPEK PERKEMBANGAN ANAK USIA DINI 5-6 TAHUN BERDASARKAN STRANDAR NASIONAL PENDIDIKAN ANAK USIA DINI. NANAEKE: Indonesian Journal of Early Childhood Education, 2(1), 52-65. 
Suwito, A. (2012). Integrasi Nilai Pendidikan Karakter ke dalam Mata Pelajaran Pendidikan Kewarganegaraan di Sekolah Melalui RPP. CIVIS, 2(2/Juli).

Swan, K. L., Kaff, M., \& Haas, S. (2019). Effectiveness of Group Play Therapy on Problematic Behaviors and Symptoms of Anxiety of Preschool Children. The Journal for Specialists in Group Work, 44(2), 82-98.

Sweeney, D. S., Baggerly, J., \& Ray, D. C. (2014). Group play therapy: A dynamic approach. Routledge.

Syamsurrijal, A. (2020). Bermain Sambil Belajar: Permainan Tradisional Sebagai Media Penanaman Nilai Pendidikan Karakter. ZAHRA: Research and Tought Elementary School of Islam Journal, 1(2), 1-14.

Tridonanto, A. (2014). Mengembangkan pola asuh demokratis. Elex Media Komputindo.

Wulandari, R., \& Rahmi, A. (2018). Relasi Interpersonal dalam Psikologi Komunikasi. Islamic Communication Journal, 3(1), 56-73.

Zubaedi, M. A. (2015). Desain Pendidikan Karakter. Prenada Media.

\section{Competing interests:}

The authors declare that they have no significant competing financial, professional or personal interests that might have influenced the performance or presentation of the work described in this manuscript. 